\title{
Crystal structure, NIR luminescence and X-ray computed tomography of
} $\mathrm{Nd}^{3+}: \mathrm{Ba}_{0.3} \mathrm{Lu}_{0.7} \mathrm{~F}_{2.7}$ nanospheres

Daniel González-Mancebo, ${ }^{a}$ Ana Isabel Becerro, ${ }^{a} *$ Eugenio Cantelar, ${ }^{b}$ Fernando Cussó, ${ }^{b}$ Arnaud Briat,${ }^{c}$ Damien Boyer, ${ }^{d}$ Manuel Ocaña ${ }^{a}$

${ }^{a}$ Instituto de Ciencia de Materiales de Sevilla (CSIC-US), c/Américo Vespucio, 49, 41092 Seville, Spain

${ }^{b}$ Dpto. Física de Materiales, C-04. Universidad Autónoma de Madrid, 28049 Madrid (Spain).

${ }^{c}$ Université Clermont Auvergne, UMR 1240 INSERM, 58 rue Montalembert, BP184, 63005 Clermont-Ferrand Cedex

${ }^{d}$ Université Clermont Auvergne, CNRS, SIGMA Clermont, Institut de Chimie de Clermont-Ferrand, F-63000 Clermont-Ferrand, France

*Corresponding author: anieto@icmse.csic.es. Phone no: +34 954489545

Keywords: nanospheres;rare earth fluorides;luminescence;computed tomography 


\begin{abstract}
Uniform, hydrophilic $50 \mathrm{~nm}$ diameter $\mathrm{Nd}^{3+}$-doped $\mathrm{Ba}_{0.3} \mathrm{Lu}_{0.7} \mathrm{~F}_{2.7}$ nanospheres are synthesized at $120^{\circ} \mathrm{C}$ using a singular one-pot method based on the use of ethylene glycol as solvent, in the absence of any additive. The composition and crystal structure of the undoped material are analyzed in detail using ICP and XRD, which reveals a $\mathrm{BaF}_{2}$ cubic crystal structure that is able to incorporate $70 \mathrm{~mol} \%$ of $\mathrm{Lu}$ ions. This finding contrasts with the reported phase diagram of the system, where the maximum solubility is around $30 \mathrm{~mol} \% \mathrm{Lu}$. XRD proves as well that the $\mathrm{Ba}_{0.3} \mathrm{Lu}_{0.7} \mathrm{~F}_{2.7}$ structure is able to incorporate $\mathrm{Nd}^{3+}$ ions up to, at least $10 \mathrm{~mol} \%$, without altering the uniform particles morphology. The Nd-doped particles exhibit near-infrared luminescence when excited at $810 \mathrm{~nm}$. The maximum emission intensity with the minimum concentration quenching effect is obtained at $1.5 \% \mathrm{Nd}$ doping level. X-ray computed tomography experiments are carried out on powder samples of the latter composition. The sample significantly absorbs X-ray photons, thus demonstrating that the $\mathrm{Nd}^{3+}$-doped $\mathrm{Ba}_{0.3} \mathrm{Lu}_{0.7} \mathrm{~F}_{2.7}$ nanospheres are good candidates as contrast agents in computed tomography.
\end{abstract}




\section{INTRODUCTION}

With the emergence of luminescent nanomaterials for biotechnological (imaging and sensing) applications, much of the recent work over the last decade has been focused on the search for alternatives to organic dye- and quantum dot-based probes. Although the latter offer several advantages relative to organic dyes, such as narrower emission profiles and photostability, they do show several shortcomings, mainly related to cytotoxicity and inadequacy to deep-tissue probing due to the low penetration of the UV and visible excitation sources. In the past few years, lanthanide(Ln)-doped rare earth(RE)-based nanoparticles have emerged as an alternative to current imaging probes. The singular optical properties of $\mathrm{Ln}^{3+}$ ions, coming from their $4 f$ electrons, confer however advantageous optical characteristics to $\mathrm{Ln}^{3+}$-activated materials including excellent photostability, large Stokes/anti-Stokes shifts, long luminescent lifetimes, and sharp emission bands, ${ }^{1,2}$ Because of these advantages along with their much lower toxicity, lanthanides are considered as very attractive luminescent supporters for biotechnological applications such as bioimaging, ${ }^{3,4}$ biosensing, ${ }^{5}$ and therapy, even though they present certain limitations mainly related to their low global intensity luminescence. Among lanthanides, $\mathrm{Nd}^{3+}$ is particularly interesting because it is excited and emits within the first and second biological windows $(650 \mathrm{~nm}-950 \mathrm{~nm}$ and $1000-1400 \mathrm{~nm}$ ), in which the radiation is weakly attenuated by tissues and can penetrate more deeply than the visible light, thus improving the sensitivity of the assays and lowering tissue damage. ${ }^{6,7,8,9}$

Most of the $\mathrm{Ln}^{3+}$-doped rare earth-based matrices classically studied, such as oxides, vanadates, phosphates, etc., show associated phonon energies that are usually very high resulting in low luminescent efficiencies due to the enhancement of non-radiative

pathways. ${ }^{10}$ A straightforward solution to this problem came with the development of fluoride-based matrices, which showed a high luminescent efficiency due to their low phonon energies. ${ }^{11}$ Most reports in the literature have been focused on the development of $\mathrm{Ln}^{3+}$-doped $\mathrm{NaREF}_{4}$ and $\mathrm{REF}_{3}(\mathrm{RE}=$ mainly $\mathrm{Y}$ and to a lesser extent $\mathrm{Gd}, \mathrm{La}$, and $\mathrm{Lu})$ phases. However, little attention has been paid to the study of $\mathrm{Ba}_{1-\mathrm{x}} \operatorname{Ln}_{\mathrm{x}} \mathrm{F}_{2+\mathrm{x}}$ nanoparticles, which have been shown to be excellent upconversion bioprobes as well as optimal contrast agents for X-ray computed tomography due to the large K-edge value and high X-ray mass absorption coefficients of $\mathrm{Ba}^{2+}$ and $\mathrm{Ln}^{3+}$ ions. Specifically, and to the best of our knowledge, only six reports have been published about the 
synthesis and optical properties of $\mathrm{BaLuF}_{5}$-based nanoparticles. Sarkar et al. ${ }^{12,13}$ Lei et al. ${ }^{14}$ and Rao et al. ${ }^{15}$ synthesized $\mathrm{Yb}^{3+}, \mathrm{Er}^{3+}: \mathrm{BaLuF}_{5}$ monodisperse nanoparticles which showed high luminescence efficiency for bio-imaging applications. Using a layer by layer strategy, Zhang et al. ${ }^{16}$ reported ultra-small $\mathrm{BaLuF}_{5}: \mathrm{Yb}, \mathrm{Er} @ \mathrm{BaLuF}_{5}: \mathrm{Yb}$ activecore-active shell nanoparticles that were able to enhance the UC and DC fluorescence by 52 and 9.8 times. In all these cases, oleic acid was used as capping agent, thus rendering hydrophobic particles, not suitable for bio-applications, thus needing a second step to make them water dispersible. Finally, Rao et al. ${ }^{17}$ presented an oleic acid-free method to synthesize PEG modified $\mathrm{BaLuF}_{5}: \mathrm{Gd} / \mathrm{Yb} / \mathrm{Er}$ nanoparticles for dual-modal luminescence and X-ray bioimaging; the method, however, rendered mixed cubic $\mathrm{BaLuF}_{5}$ and monoclinic $\mathrm{BaLu}_{2} \mathrm{~F}_{8}$ particles. Another oleic acid-free method was reported by Grzyb et al. ${ }^{18}$ based on the use of microwaves as the heating source, which did not produce discrete $\mathrm{BaLuF}_{5}$ nanoparticles.

In this paper we report, for the first time, the synthesis of hydrophilic, $50 \mathrm{~nm}$-diameter Nd-doped barium-lutetium fluoride nanoparticles, with excitation and emission in the biological windows, using a one-step process in the absence of any additives and using much lower temperatures than the methods reported above. Nanoparticles with different $\mathrm{Nd}^{3+}$ doping levels were synthesized to find the optimum composition of the optical probe by measuring lifetime values. Finally, the ability of the synthesized bariumlutetium fluoride nanoparticles as a contrast agent for X-ray computed tomography was evaluated.

\section{EXPERIMENTAL SECTION}

\section{Synthesis of samples}

The barium-lutetium fluoride nanoparticles were obtained according to the following method: barium nitrate $\left(\mathrm{Ba}\left(\mathrm{NO}_{3}\right)_{2}\right.$, (Sigma Aldrich, $\left.\geq 99 \%\right)$ and lutetium acetate $\left(\mathrm{Lu}(\mathrm{OAc})_{3}\right)$ hydrate $\left(\left(\mathrm{CH}_{3} \mathrm{CO}_{2}\right)_{3} \mathrm{Lu} \cdot \mathrm{xH}_{2} \mathrm{O}\right.$, Sigma Aldrich, 99.9\%) were dissolved, with magnetic stirring at $70{ }^{\circ} \mathrm{C}$, in $9.5 \mathrm{~mL}$ of ethylene glycol (EG, Panreac). The solution was then cooled down to room temperature and admixed with $0.5 \mathrm{~mL}$ of 1 butyl-3-methylimidazolium tetrafluoroborate ([BMIM]BF 4 , Aldrich, $\geq 97 \%$ ), which was added dropwise to the solution. The resulting solution (final concentration of $\mathrm{Ba}$ and 
$\mathrm{Lu}=0.01 \mathrm{M}$ for each cation) was magnetically stirred for 5 minutes at room temperature to favor homogenization and aged for 15 hours in tightly closed test tubes using an oven preheated at $120{ }^{\circ} \mathrm{C}$. The resulting dispersion was cooled down to room temperature, centrifuged to remove the supernatants and washed, twice with ethanol and once with double distilled water. For some analyses, the powders were dried at room temperature. Different $\mathrm{Lu}^{3+}$ and $\mathrm{F}^{-}$sources were used to analyze their effect on the particles characteristics. The Lu sources were lutetium nitrate $\left(\mathrm{Lu}\left(\mathrm{NO}_{3}\right)_{3}\right.$, Sigma Aldrich, 99.99\%) and lutetium acetylacetonate $\left(\left[\mathrm{CH}_{3} \mathrm{COCHC}(\mathrm{O}) \mathrm{CH}_{3}\right]_{3} \mathrm{Lu} \cdot \mathrm{xH}_{2} \mathrm{O}\right.$, Sigma Aldrich, $\geq 99.9 \%$ ), while ammonium fluoride $\left(\mathrm{NH}_{4} \mathrm{~F}\right.$, Sigma Aldrich, 99.99\%) and sodium tetrafluoroborate $\left(\mathrm{NaBF}_{4}\right.$, Sigma Aldrich $\left.>98 \%\right)$ were used as alternative fluoride sources. We also used solvents other than ethylene glycol, such as glycerol (Panreac, 99.99\%), butylene glycol (Fluka, 99.5\%) and diethylene glycol (Sigma, 99.5\%), to analyze the effect of the polyol nature on the particles morphology. Likewise, the experiment was also carried out using a microwaves oven instead of the conventional heating oven to check the possible influence of the heating source on the particles characteristics.

The $\mathrm{Nd}^{3+}$-doped particles were synthesized following the same procedure and using neodymiun nitrate hydrate $\left(\mathrm{Nd}_{(}\left(\mathrm{NO}_{3}\right)_{3} \cdot \mathrm{xH}_{2} \mathrm{O}\right.$, Sigma Aldrich, 99.9\%) in variable amounts. The lanthanide ions $(\mathrm{Lu}+\mathrm{Nd})$ concentration was kept constant $(0.01$ $\left.\mathrm{mol} \cdot \mathrm{dm}^{-3}\right)$ in all experiments, whereas the $\mathrm{Nd} /(\mathrm{Lu}+\mathrm{Nd})$ molar ratio was varied from $0.25 \%$ to $2.5 \%$.

\section{Characterization techniques}

The shape and size of the particles was examined by transmission electron microscopy (TEM, Philips 200CM). Particle size distributions were obtained from the micrographs by counting several hundreds of particles, using the free software ImageJ. Additional information on the size and colloidal stability of the particles in aqueous suspension $(0.5$ $\mathrm{mg} \cdot \mathrm{mL}^{-1}$ of solid) was obtained from Dynamic Light Scattering (DLS) measurements. The experiments were carried out using a Malvern Zetasizer Nano-ZS90 equipment, which was used as well to measure the Zeta potential of the suspensions.

The crystalline structure of the prepared particles was assessed by X-ray diffraction $(X R D)$ using a Panalytical, $\mathrm{X}^{\prime}$ Pert Pro diffractometer $(\mathrm{CuK} \alpha)$ with an $\mathrm{X}$-Celerator detector over an angular range of $10^{\circ}<2 \theta<120^{\circ}, 2 \theta$ step width of $0.02^{\circ}$, and $10 \mathrm{~s}$ 
counting time. Silicon was used as internal standard. The TOPAS software (TOPAS version 4.2, Bruker AXS, 2009) was used to calculate the unit cell volume of the barium-lutetium structure using the Rietveld method. ${ }^{19}$ Refined parameters were background coefficients, scale factor, zero, unit cell parameters, displacement parameters of $\mathrm{Ba}^{2+}$ and $\mathrm{Lu}^{3+}$ and profile parameters. The isomorphic substitution of $\mathrm{Nd}^{3+}$ by $\mathrm{Lu}^{3+}$ in the barium-lutetium fluoride crystal structure was proved as well by determination and comparison of unit cell parameters of the undoped and $\mathrm{Nd}^{3+}$-doped nanoparticles.

The quantitative composition of the samples was analyzed by inductively coupled plasma atomic emission spectroscopy (ICP-AES, Horiba Jobin Yvon, Ultima 2). The powder samples were previously dissolved in hydrochloride acid.

The emission spectra of the $\mathrm{Nd}^{3+}$-doped $\mathrm{Ba}_{0.3} \mathrm{Lu}_{0.7} \mathrm{~F}_{2.7}$ particles were recorded under $\mathrm{cw}$ excitation using a diode laser @ $810 \mathrm{~nm}$ (B\&W Tek) as excitation source. For that purpose, the powder samples were placed filling a tiny hole ( $3 \mathrm{~mm}$ diameter) practiced in an aluminum foil and sandwiched between two microscope slides. This arrangement allows not only keeping an approximately constant amount of sample, but also preserving the geometry for reproducible luminescence measurements. Fluorescence was analyzed through an ARC monochromator model SpectraPro 500-i and then detected using an AsGaIn photodiode.

Lifetime measurements were obtained under pulsed excitation using a MOPO@ $\lambda_{\mathrm{exc}}=$ $810 \mathrm{~nm}$ (pulse width $10 \mathrm{~ns}$ and $10 \mathrm{~Hz}$ repetition rate) and recording the luminescence decay at $\lambda_{\text {exc }}=1056 \mathrm{~nm}$, associated to the ${ }^{4} \mathrm{~F}_{3 / 2} \rightarrow{ }^{4} \mathrm{I}_{11 / 2}$ transition. The signal was recorded and averaged using a Tektronix DPO4104B-L digital oscilloscope.

Micro-CT (eXplore CT120; GE HealthCare) examinations were performed using the following parameters: acquisition consisted of 720 views acquired, with a $20 \mathrm{~ms}$ exposure time per view (Gain: 25 and Offset: 20). X-ray tube voltage and current were set at $100 \mathrm{kV}$ and $50 \mathrm{~mA}$. CT images were reconstructed using a binning mode of $1 \mathrm{x} 1 \mathrm{x} 1$ and a voxel size of 50x50x50 $\mu \mathrm{m} 3$. Images were analyzed using MicroView analysis + software (version 2.2, GE Healthcare).

\section{RESULTS AND DISCUSSION}




\section{Synthesis, morphology and crystal structure of the Ba,Lu fluoride nanoparticles.}

It is well known that uniform particles can be obtained by precipitation through a slow and controlled release of the precipitating anions or cations in the reaction medium. ${ }^{20}$ We have used, in the present study, a strategy based on the controlled release of fluoride anions using an ionic liquid $\left([\mathrm{BMIM}] \mathrm{BF}_{4}\right)$. The required fluoride anions are liberated by the ionic liquid as a consequence of its hydrolysis with the hydration water molecules of the lutetium and barium precursors. ${ }^{21}$ Ionic liquids are non-volatile, non-flammable and thermally stable organic salts with low melting point, which show a superior capability for the solvation and stabilization of metal ions. The use of [BMIM] $\mathrm{BF}_{4}$ in our reaction system has, therefore, a double purpose: it is the source of fluoride anions and can act in turn as a capping agent during the particles growth. Ethylene glycol (EG) was selected as solvent because polyols have been amply shown to be suitable solvents for the synthesis of nanomaterials, as they may act not only as solvent but also as capping agents, thus limiting particle growth. ${ }^{22}$ Based on this strategy, we have obtained uniform, spherical, and well dispersed particles of $50 \mathrm{~nm}$ diameter after aging at $120^{\circ} \mathrm{C}$ for 15 hours in a conventional oven an EG solution of lutetium acetate $(0.01 \mathrm{M})$, barium nitrate $(0.01 \mathrm{M})$ and $\left[\mathrm{BMIM} \mathrm{BF}_{4}(0.18 \mathrm{M})\right.$. Figure $1 \mathrm{a}$ and $1 \mathrm{~b}$ show, respectively, a TEM micrograph of such particles and the corresponding size distribution plot, obtained by measuring particles diameter in TEM micrographs. The hydrodynamic diameter plot obtained by DLS in a fresh aqueous suspension of the particles is shown in Figure 1c. The mean hydrodynamic diameter value was $80(20) \mathrm{nm}$, which is slightly higher than the TEM diameter, indicating a minimal aggregation of the particles in water. The Zeta potential value obtained in the same aqueous solution $(\mathrm{pH}=5.4)$ was $38(10) \mathrm{mV}$, which indicated that the particles dispersion is caused by electrostatic repulsion forces.

The mentioned experimental conditions were found to be very critical to produce uniform particles since changing only one of the different experimental parameters used and leaving all the others unaltered (precursors' nature and concentration, solvent nature, reaction temperature, and heating system -conventional oven and microwaves oven) led to rather heterogeneous systems (Figures S1-S3). This fact must be assigned, in agreement with the Lamer and Dinegar classical theory, ${ }^{23}$ to variations in the kinetics of precipitation induced when altering the experimental conditions, which affect the nucleation and growth processes. 
The composition of the obtained nanoparticles was analyzed by EDX spectroscopy, which showed that the particles were composed of $\mathrm{Ba}, \mathrm{Lu}$ and $\mathrm{F}$ (Figure 2a). The quantitative analysis of the sample by means of ICP spectroscopy revealed a $\mathrm{Ba} / \mathrm{Lu}$ molar ratio of 30/70, which is significantly lower than the nominal value (50/50) and indicates a $\mathrm{Ba}_{0.3} \mathrm{Lu}_{0.7} \mathrm{~F}_{2.7}$ stoichiometry. This observation has not been reported in the previous studies of $\mathrm{BaLuF}_{5}$ nanoparticles obtained by homogeneous precipitation, $12,13,14,15,16,17$ probably due to the fact that none of them carried out a quantitative analysis of the material and just based their stoichiometry on the nominal $\mathrm{Ba}$ and $\mathrm{Lu}$ contents $(50 \mathrm{~mol} \%)$ used in their syntheses. However, higher Ba-containing phases $\left(\mathrm{Ba}_{1-\mathrm{x}} \mathrm{Lu}_{\mathrm{x}} \mathrm{F}_{2+\mathrm{x}}\right.$ with $\left.\mathrm{x}=0.1,0.182,0.25\right)$ have been obtained in the form of single crystals. ${ }^{24}$ The formation of the Ba30-Lu70 phase in our case could be due either to the synthesis conditions (homogeneous precipitation at $120{ }^{\circ} \mathrm{C}$ versus the high temperature treatments necessary to obtain single crystals) or to a lower precipitation rate of $\mathrm{Ba}^{2+}$ compared with that of $\mathrm{Lu}^{3+}$. To clarify this point, we have synthesized the particles from a starting solution containing a Ba:Lu 0.3:0.7 stoichiometry. Both the XRD pattern and the EDX analysis (Fig. S4) showed the formation of the Ba30-Lu70 phase, which allows concluding that the final stoichiometry of the sample is very likely constraint by the synthesis conditions.

The crystal structure of the as-prepared particles was studied by XRD (Figure 2b). All reflections in the pattern matched well with those of cubic $\mathrm{BaF}_{2}$ (PDF 00-004-0452, ICDD 2015), although a significant shift of the reflections towards higher $2 \theta$ values was observed, which indicates a substantial change in lattice parameters. This change is likely due to the different ionic radii of $\mathrm{Ba}^{2+}$ and $\mathrm{Lu}^{3+}(1.42 \AA$ and $0.977 \AA$, respectively, in VIII coordination), as well as to the extra fluoride anions present in the structure to balance the excess positive charge due to the heterovalent substitution. We have carried out a LeBail refinement of the structure with the TOPAS software using as starting parameters those of $\mathrm{BaF}_{2}$ in space group $F m-3 m$. A unit cell volume of 184.66(6) $\AA^{3}$ was obtained for our sample. The unit cell volumes reported in the literature for several Lu-containing $\mathrm{BaF}_{2}$ compositions $(10,16.5,18 \text {, and } 25 \mathrm{~mol} \% \mathrm{Lu})^{24}$ as well as the one reported for pure $\mathrm{BaF}_{2}$ (PDF 00-004-0452, ICDD 2015) were plotted in Figure 2c versus the corresponding Lu content. All the reported data points were successfully fitted to a straight line, which extrapolated exactly to our value for the 70 mol \% Lu, thus indicating that the solid solubility of $\mathrm{Lu}^{3+}$ in $\mathrm{BaF}_{2}$ stands up to, at least, 
$70 \%$ in the experimental conditions of our reaction. This finding also demonstrates the robustness of the cubic crystal structure of $\mathrm{BaF}_{2}$ in these conditions. The solid solubility extent differs however significantly from the phase diagram of the $\mathrm{BaF}_{2}-\mathrm{LuF}_{3}$, where the maximum solubility of $\mathrm{LuF}_{3}$ in $\mathrm{B} \mathrm{aF}_{2}$ is around $30 \mathrm{~mol} \%$ and an intermediate compound is reported for the $30 \mathrm{~mol} \% \mathrm{BaF}_{2}-70 \mathrm{~mol}^{2} \mathrm{LuF}_{3}$ composition, which is not observed in our study. ${ }^{25}$ This difference is very likely due to the fact that the phase diagram was described at temperatures ranging from $800^{\circ} \mathrm{C}$ up to the melting points, while our composition has only been heated at $120^{\circ} \mathrm{C}$ in ethylene glycol. Finally, in order to know whether the particles are monocrystalline or polycrystalline, the Scherrer formula was applied to the two most intense reflections located in the $30-50^{\circ} 2 \theta$ range. An average crystallite size of $11.5 \mathrm{~nm}$ was obtained, which is well below the dimensions of the nanoparticles $(50 \mathrm{~nm})$. This result suggests that the nanoparticles are formed by smaller constituent subunits, as also observed for related particle systems. ${ }^{26}$

\section{Synthesis and Characterization of the $N d: B a_{0.3} L_{0.7} F_{2.7}$ Nanoparticles}

$\mathrm{Nd}^{3+}$-doped $\mathrm{Ba}_{0.3} \mathrm{Lu}_{0.7} \mathrm{~F}_{2.7}$ nanoparticles with different $\mathrm{Nd}$ contents $(0.25,0.5,1.0,1.5$, and $2.5 \mathrm{~mol} \% \mathrm{Nd}$ ) were synthesized using the method reported above for the undoped material, and adding the corresponding amount of neodymium nitrate in each case. It was found that the doping process did not alter either the shape or the size of the undoped particles irrespective of the doping level used (Figure $3 a$ and $3 b$ ). The XRD patterns of the different $\mathrm{Nd}^{3+}: \mathrm{Ba}_{0.3} \mathrm{Lu}_{0.7} \mathrm{~F}_{2.7}$ samples were very similar to each other and to the one of the undoped material (Figure 3c) and no extra reflections could be observed at any doping level. This result indicates that the cubic $\mathrm{Ba}_{0.3} \mathrm{Lu}_{0.7} \mathrm{~F}_{2.7}$ crystal structure was not affected by the doping process. The unit cell volume value for each Nd-doped sample $(0,0.25,0.5,1.5$, and $2.5 \% \mathrm{Nd})$ was calculated using the Rietveld method $^{19}$ to assess the ionic substitution mechanism in the $\mathrm{Ba}_{0.3} \mathrm{Lu}_{0.7} \mathrm{~F}_{2.7}$ structure. The values obtained were plotted in Figure $3 \mathrm{~d}$. In case $\mathrm{Nd}^{3+}$ substituted exclusively the $\mathrm{Lu}^{3+}$ ions, a linear increase in the unit cell volume would be expected given the bigger ionic radius of the former compared to the latter (ionic radii: $\mathrm{Nd}^{3+}=1.109 \AA, \mathrm{Lu}^{3+}=0.977 \AA$ ). This is not however the case, since, although the volume values increased linearly with increasing $\mathrm{Nd}^{3+}$ content, such trend was non-linear for $\mathrm{Nd}$ contents $\geq 1.5 \mathrm{~mol} \%$. Two explanations for this observation were plausible: 
i) the system reached the maximum $\mathrm{Nd}$ solubility at $\mathrm{Nd}$ contents $\geq 1.5$ mol \%, the excess $\mathrm{Nd}$ forming a secondary Nd-rich phase, and

ii) $\quad \mathrm{Nd}$ substituted Lu at very low doping levels $(<1.5 \%)$ thus leading to a linear increase in lattice parameters; however, at higher $\mathrm{Nd}$ contents $\mathrm{Nd}$ substituted both $\mathrm{Ba}$ and $\mathrm{Lu}$, which would break the linearity given the higher ionic radius of $\mathrm{Ba}^{2+}(1.42 \AA)$.

We have synthesized two new samples containing 5\% and $10 \% \mathrm{Nd}$ and no reflections other than those corresponding to the cubic phase were observed in their XRD patterns (Figure S5), which rules out our first hypothesis. The unit cell volume calculated for those two new samples were $186.13 \AA^{3}$ and $186.97 \AA^{3}$, respectively. No clear linear relationship is observed between volume and $\mathrm{Nd}$ content (Figure $3 \mathrm{~d}$ ). These results support our second hypothesis about the substitution of $\mathrm{Nd}$ by both $\mathrm{Ba}$ and $\mathrm{Lu}$ in the crystalline structure.

\section{Luminescence of the $\mathrm{Nd}: \mathrm{Ba}_{0.3} \mathrm{Lu}_{0.7} \mathrm{~F}_{2.7}$ Nanoparticles}

The emission spectra of the $\mathrm{Nd}: \mathrm{Ba}_{0.3} \mathrm{Lu}_{0.7} \mathrm{~F}_{2.7}$ nanoparticles were recorded using a continuous wave diode at $\lambda_{\text {exc }}=810 \mathrm{~nm}$, which efficiently populates the ${ }^{4} \mathrm{~F}_{5 / 2}:{ }^{2} \mathrm{H}_{9 / 2}$ multiplet, which then populates the ${ }^{4} \mathrm{~F}_{3 / 2}$ state via nonradiative relaxation, from where the different near infrared (NIR) emissions originate (see $\mathrm{Nd}^{3+}$ energy levels diagram in Figure S6). Indeed, the emission spectra of the samples (Figure 4a) showed emissions at $\sim 875 \mathrm{~nm}, \sim 1056 \mathrm{~nm}$ and $\sim 1325 \mathrm{~nm}$, corresponding, respectively, to the transitions from the excited ${ }^{4} \mathrm{~F}_{3 / 2}$ level to the ${ }^{4} \mathrm{I}_{9 / 2},{ }^{4} \mathrm{I}_{11 / 2}$ and ${ }^{4} \mathrm{I}_{13 / 2}$ lower lying levels. Both the excitation and the first emission bands are located inside the first biological window (650 nm $950 \mathrm{~nm}$ ), while the two low energy emission bands are inside the second biological window $(1000 \mathrm{~nm}-1400 \mathrm{~nm})$. In these spectral ranges, the radiation is weakly attenuated by tissues and can penetrate more deeply than the visible light, thus improving the sensitivity of the bioassays. ${ }^{6}$

Figure $4 \mathrm{a}$ shows as well that the emission intensity increased with increasing $\mathrm{Nd}$ content. To better illustrate this result, the peak intensity of the band at $\sim 1056 \mathrm{~nm}$ has been plotted in Figure $4 \mathrm{~b}$ versus the nominal $\mathrm{Nd}$ content. A linear increase of the emission intensity can be observed up to $1.5 \mathrm{~mol} \% \mathrm{Nd}$, while it slightly decreased for the $2.5 \mathrm{~mol} \% \mathrm{Nd}$ sample, which suggests a possible concentration quenching effect in the last sample. To confirm this hypothesis and establish the optimum $\mathrm{Nd}$ doping level, 
luminescence decay curves corresponding to the ${ }^{4} \mathrm{~F}_{3 / 2} \rightarrow{ }^{4} \mathrm{I}_{11 / 2}$ electronic transition were recorded for all $\mathrm{Nd}$-doped samples using the pulsed excitation provided by a MOPO $\left(\lambda_{\text {exc }}=810 \mathrm{~nm}\right)$ (Figure S7). A rise can be observed at the very beginning of the detection period, corresponding to the filling of the emitting ${ }^{4} \mathrm{~F}_{3 / 2}$ level from the upper ${ }^{4} \mathrm{~F}_{5 / 2}:{ }^{2} \mathrm{H}_{9 / 2}$ multiplet convoluted with the temporal response of the detection system. The decay curves showed, after the initial rise, an exponential decay that can be fitted using a bi-exponential temporal dependence of the form

$$
I(t)=I_{01} \exp \left(-t / \tau_{1}\right)+I_{02} \exp \left(-t / \tau_{2}\right)
$$

for all the compositions (solid lines in Figure S7). The corresponding fitting parameters are summarized in Table 1 . The individual lifetime values $\left(\tau_{1}\right.$ and $\left.\tau_{2}\right)$ have also been plotted in Figure $4 \mathrm{c}$ versus $\mathrm{Nd}$ doping level. The long lifetime has classically been assigned to the luminescent centers located in the interior of the nanoparticle while the short lifetime corresponds to the active ions on the nanoparticle surface, where the hydroxyl species, detected in the FTIR spectrum, act as luminescence quenchers, thus increasing the decay rate. ${ }^{27}$

It can be observed that, when increasing $\mathrm{Nd}$ concentration, the short component $\left(\tau_{1}\right)$ remained basically constant while the long component $\left(\tau_{2}\right)$ showed some decrease as $\mathrm{Nd}$ concentration increased (concentration quenching).

The average decay time, $<\tau>$, defined as:

$$
\langle\tau\rangle=\frac{\int_{t_{0}}^{t_{f}} t I(t) d t}{\int_{t_{0}}^{t_{f}} I(t) d t}=\left(\tau_{1}^{2} I_{1}+\tau_{2}^{2} I_{2}\right) /\left(\tau_{1} I_{1}+\tau_{2} I_{2}\right)
$$

has also been shown in Table 1 and plotted in Figure $4 \mathrm{~d}$ versus the $\mathrm{Nd}$ doping level. The quenching of the lifetime long component implies a parallel quenching of the average values (Figure 4d). It can be observed that average lifetime values stayed nearly constant at low $\mathrm{Nd}$ contents $(\leq 1.5 \mathrm{~mol} \%)$, while the lifetime slightly dropped at $[\mathrm{Nd}]=$ $2.5 \mathrm{~mol} \%$ as a consequence of the concentration quenching effect. ${ }^{28}$ Therefore, the $1.5 \%$ $\mathrm{Nd}$ doping level produced the maximum emission intensity with the minimum concentration quenching effect, thus resulting in a maximum efficiency. 


\section{X-ray Computed Tomography}

$\mathrm{X}$-ray computed tomography images have been recorded on the $1.5 \% \mathrm{Nd}$ doped $\mathrm{Ba}_{0.3} \mathrm{Lu}_{0.7} \mathrm{~F}_{2.7}$ nanoparticles as a powder in a plastic tube. Figure 5a, showing a transversal image, evidenced that the nanoparticles significantly absorbed the X-ray photons since the image exhibits a suitable contrast. In order to confirm this assertion, an absorption profile, shown in Figure 5b, was generated from this transversal image. The difference between the lowest and the highest intensity is consistent with a high contrast image.

\section{CONCLUSIONS}

Uniform, $50 \mathrm{~nm}$ diameter, hydrophilic $\mathrm{Nd}^{3+}$-doped $\mathrm{Ba}_{0.3} \mathrm{Lu}_{0.7} \mathrm{~F}_{2.7}$ nanoparticles have been synthesized using a simple one-pot precipitation method consisting in the aging of an ethylene glycol solution containing lutetium acetate, barium nitrate and a fluoridebased ionic liquid. The undoped material showed a cubic crystal structure compatible with the formation of defect clusters containing $\mathrm{Lu}^{3+}$ ions while the remaining part of the crystal (matrix) preserved the structure and composition of initial $\mathrm{BaF}_{2}$. The $\mathrm{Ba}_{0.3} \mathrm{Lu}_{0.7} \mathrm{~F}_{2.7}$ structure is able to incorporate $\mathrm{Nd}^{3+}$ ions up to at least $10 \%$ altering neither the particle morphology nor the cubic structure. The Nd-doped nanoparticles exhibited near-infrared luminescence when excited at $810 \mathrm{~nm}$. The $1.5 \% \mathrm{Nd}$-doped $\mathrm{Ba}_{0.3} \mathrm{Lu}_{0.7} \mathrm{~F}_{2.7}$ produced the maximum emission intensity with the minimum concentration quenching effect. The later nanoparticles absorbed X-ray photons and demonstrated to be useful as contrast agents in X-ray computed tomography. In summary, the proposed method allows synthesizing hydrophilic $50 \mathrm{~nm} \mathrm{Nd:Ba}{ }_{0.3} \operatorname{Lu}_{0.7} \mathrm{~F}_{2.7}$ nanoparticles, which are excited and emit in the biological windows and are good potential candidates for bioimaging applications.

\section{SUPPORTING INFORMATION}

TEM micrographs of the precipitates obtained after changing only one of the parameters used to synthesize the uniform $\mathrm{Ba}_{0.3} \mathrm{Lu}_{0.7} \mathrm{~F}_{2.7}$ nanoparticles shown in Figure 1 of the paper (Figures SI1, SI2 and SI3). XRD patterns and EDX spectra of the samples obtained from nominal compositions $0.5 \mathrm{Ba}: 0.5 \mathrm{Lu}$ and $0.3 \mathrm{Ba}: 0.3 \mathrm{Lu}$ (Figure S4). XRD 
patterns of the undoped and $\mathrm{Nd}$-doped (5\% and 10\%) $\mathrm{Ba}_{0.3} \mathrm{Lu}_{0.7} \mathrm{~F}_{2.7}$ samples (Figure $\mathrm{S} 5) . \mathrm{Nd}^{3+}$ electronic energy levels diagram showing the non-radiative and radiative decays after excitation at $808 \mathrm{~nm}$ (Figure S6). Temporal evolution of the ${ }^{4} \mathrm{~F}_{3 / 2}-{ }^{4} \mathrm{I}_{11 / 2}$ luminescence for the $\mathrm{Ba}_{0.3} \mathrm{Lu}_{0.7} \mathrm{~F}_{2.7}$ nanophosphors doped with 0.5, 1.0, 1.5 and 2.5 $\mathrm{mol} \% \mathrm{Nd}^{3+}$ (excitation at $810 \mathrm{~nm}$ using a MOPO system). (Figure $\mathrm{S} 7$ ).

\section{ACKNOWLEDGEMENTS}

This work has been supported by the Spanish Ministry of Economy and Competitiveness (MINECO) (MAT2014-54852-R and MAT2012-34919), CSIC (PIE 201560E056 and 201460E005). Imaging experiments were conducted within the multimodal imaging platform IVIA, Clermont-Ferrand, France. 


\section{REFERENCES}

1 K. Binnemans, Chem. Rev., 2009, 109, 4283.

2 S. V. Eliseeva and J.-C. G. Bünzli, Chem. Soc. Rev., 2010, 39, 189.

3 J. Shen, L.-D. Sun and C.-H. Yan, Dalton Trans., 2008, 42, 5687.

4 A. I. Becerro, J. Criado, L. C. Gontard, S. Obregón, A. Fernández, G. Colón and M. Ocaña, Cryst. Growth Des., 2014, 14, 3319.

5 A. Escudero, C. Carrillo-Carrión, M. V Zyuzin, S. Ashraf, R. Hartmann, N. O. Núñez, M. Ocaña and W. J. Parak, Nanoscale, 2016, 8, 12221.

6 U. Rocha, K. U. Kumar, C. Jacinto, I. Villa, F. Sanz-Rodríguez, M. Iglesias De La

Cruz, A. Juarranz, E. Carrasco, F. C. J. M. Van Veggel, E. Bovero, J. García Solé and D. Jaque, Small, 2014, 10, 1141.

7 G. Chen, T. Y. Ohulchanskyy, S. Liu, W. C. Law, F. Wu, M. T. Swihart, H. Ågren and P. N. Prasad, ACS Nano, 2012, 6, 2969.

8 X. Li, R. Wang and F. Zhang, Sci. Rep., 2013, 3, 3536.

9 L. Cheng, C. Wang and Z. Liu, Nanoscale, 2013, 5, 23.

10 G. Wang, Q. Peng and Y. Li, Acc. Chem. Res., 2011, 44, 322.

11 V. Mahalingam, F. Vetrone, R. Naccache, A. Speghini and J. A. Capobianco, Adv. Mater., 2009, 21, 4025.

12 S. Sarkar, C. Hazra and V. Mahalingam, Dalt. Trans., 2013, 42, 63.

13 S. Sarkar, B. Meesaragandla, C. Hazra and V. Mahalingam, Adv. Mater., 2013, 25, 856.

14 L. Lei, D. Chen, F. Huang, Y. Yu and Y. Wang, J. Alloys Compd., 2012, 540, 27.

15 L. Rao, W. Lu, H. Wang, Z. Yi, S. Zeng and Z. Li, Mater. Res. Bull., 2015, 64, 27.

16 Y. Zhang, X. Liu, Y. Lang, Z. Yuan, D. Zhao, G. Qin and W. Qin, J. Mater. Chem. C, 2015, 3, 2045.

17 L. Rao, W. Lu, T. Zeng, Z. Yi, H. Wang, H. Liu and S. Zeng, Dalton Trans., 2014, 43, 13343.

18 T. Grzyb, S. Balabhadra, D. Przybylska and M. Węcławiak, J. Alloys Compd., 2015, 649, 606.

19 H. M. Rietveld, J. Appl. Crystallogr. 1969, 2, 65.

20 E. Matijevic, Chem. Mater., 1993, 5, 412.

21 S. Jacob, L. Bitton, J. Grinblat, I. Felner, Y. Koltypin and A. Gedanken, Chem. Mater., 2006, 18, 3162.

22 C. Feldmann, Adv. Funct. Mater., 2003, 13, 101.

23 V. LaMer and R. Dinegar, J. Am. Chem. Soc., 1950, 72, 4847.

24 A. M. Golubev, L. P. Otroshchenko, V. N. Molchanov and B. P. Sobolev, Crystallogr. Reports, 2009, 54, 423.

25 B. P. Sobolev and N. L. Tkachenko, J. Less Common Metals, 1982, 85, 155.

26 A.I. Becerro, D. Gonzalez-Mancebo, M. Ocaña. Uniform, luminescent Eu:LuF 3 nanoparticles. J Nanopart Res. 2015, 17, 5.

27 J. W. Stouwdam and F. C. J. M. Van Veggel, Nano Lett., 2002, 2, 733.

28 A. I. Becerro, D. González-Mancebo, E. Cantelar, F. Cussó, G. Stepien, J. M. De La Fuente and M. Ocana, Langmuir, 2016, 32, 411. 


\section{Figure captions:}

Figure 1: a) TEM micrograph of the precipitated fluoride nanoparticles, $b$ and $c$ ) size distribution obtained from TEM images and from DLS measurement, respectively.

Figure 2: a) EDX spectrum of the nanoparticles shown in Fig. 1a. b): Experimental XRD pattern of such nanoparticles together with the Powder Diffraction File corresponding to cubic $\mathrm{BaF}_{2}$. c) Circles: Unit cell volume values reported for different $\mathrm{Ba}_{1-\mathrm{x}} \mathrm{Lu}_{\mathrm{x}} \mathrm{F}_{2+\mathrm{x}}$ compositions in ICDD ( $\mathrm{x}=0$ (PDF 00-004-0452), $\mathrm{x}=0.1$ PDF 01-078-5659, $\mathrm{x}=0.18$ PDF 01-078-5660, $\mathrm{x}=0.25$ PDF 04-011-7480), Star: Unit cell value obtained in this work for $x=0.70$. Red, solid line: linear fit of circles. Red, dashed line; extrapolation of the red, solid line to the $70 \mathrm{~mol} \% \mathrm{Lu}$ composition. Blue, dotted line: Unit cell volumes calculated for the case of a statistical distribution of $\mathrm{Lu}^{3+}$ and $\mathrm{Ba}^{2+}$ ions. The calculation has been made starting from the $\mathrm{BaF}_{2}$ unit cell volume and using the weighted ionic radii of $\mathrm{Ba}^{2+}$ and $\mathrm{Lu}^{3+}$ for each composition.

Figure 3: $a$ and b) TEM micrographs of the 0.25 and $2.5 \mathrm{~mol} \% \mathrm{Nd}$-containing $\mathrm{Ba}_{0.3} \mathrm{Lu}_{0.7} \mathrm{~F}_{2.7}$ nanoparticles. c) XRD patterns of the Nd-doped $\mathrm{Ba}_{0.3} \mathrm{Lu}_{0.7} \mathrm{~F}_{2.7}$ nanoparticles. d) Unit cell volume of the $\mathrm{Nd}$-doped $\mathrm{Ba}_{0.3} \mathrm{Lu}_{0.7} \mathrm{~F}_{2.7}$ samples versus $\mathrm{Nd}$ content The values for 5\% and 10\%-doped samples are also shown.

Figure 4: a) Emission spectra of $\mathrm{Nd}$-doped $\mathrm{Ba}_{0.3} \mathrm{Lu}_{0.7} \mathrm{~F}_{2.7}$ nanoparticles. b) Peak intensity of the Nd emission band located at $1056 \mathrm{~nm}\left({ }^{4} \mathrm{~F}_{3 / 2} \rightarrow{ }^{4} \mathrm{I}_{11 / 2}\right.$ transition $) v s$. Nd content. c) Short and long components of the lifetime calculated from the fitting of the corresponding decay curves using equation 1 and given in Table 1.d) Average lifetime $\langle\tau\rangle$ calculated from the right hand-side term of eq 2, using the corresponding fitting parameters given in Table 1, vs. Nd content. The lines are guides to the eye.

Figure 5: a) Computed tomography: maximum intensity projection image of $1.5 \% \mathrm{Nd}$ doped $\mathrm{Ba}_{0.3} \mathrm{Lu}_{0.7} \mathrm{~F}_{2.7}$ nanoparticles (transversal view) acquired at $100 \mathrm{keV}$ and $50 \mathrm{~mA}$ using a GE Healthcare CT120 scanner. b) $1.5 \% \mathrm{Nd}$ doped $\mathrm{Ba}_{0.3} \mathrm{Lu}_{0.7} \mathrm{~F}_{2.7}$ nanoparticles absorption profile generated from the transversal view (Values: hounsfield units). 
Figure 1
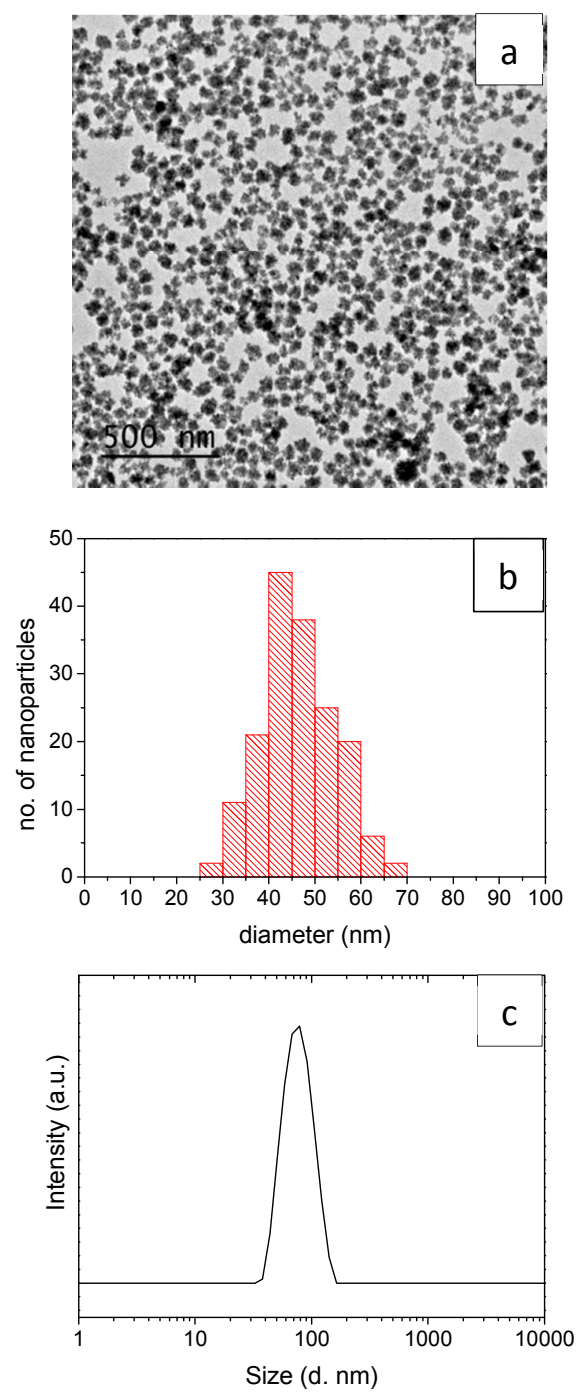
Figure 2
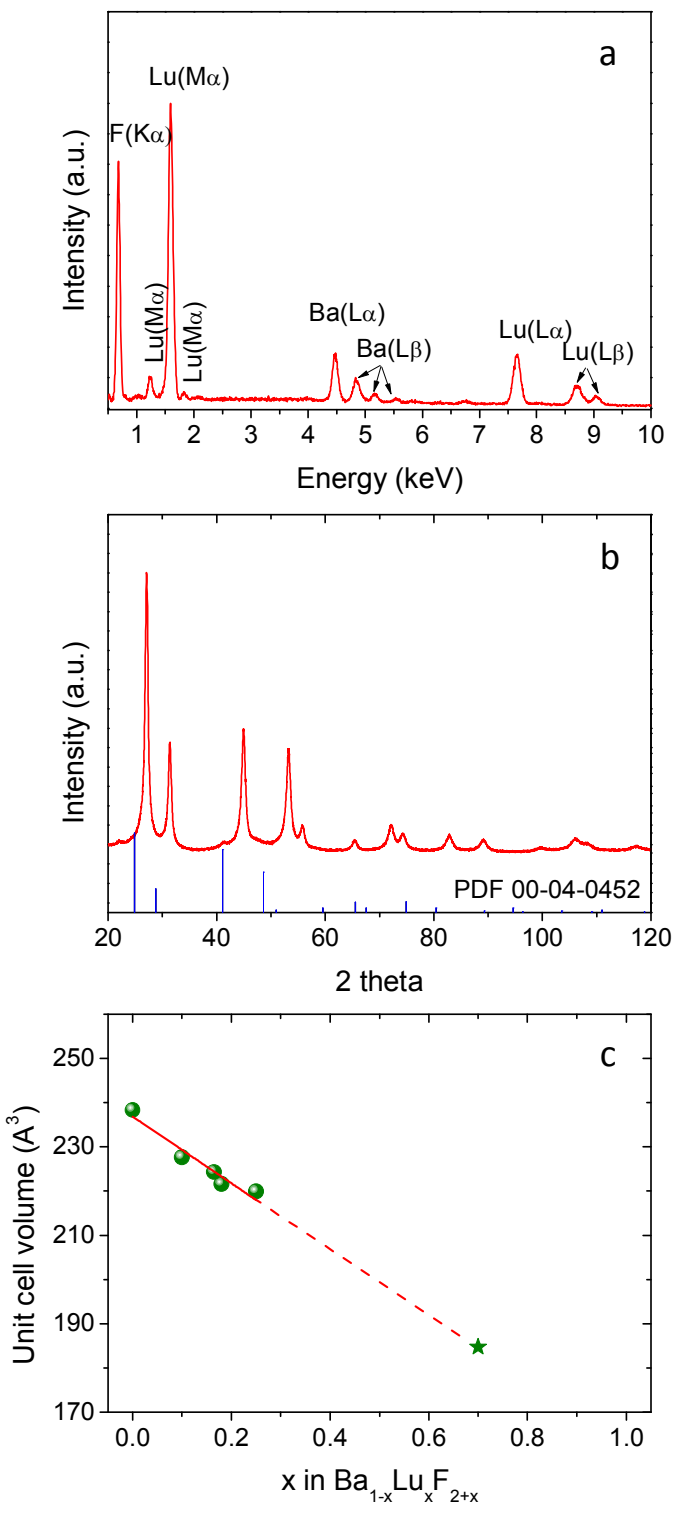
Figure 3
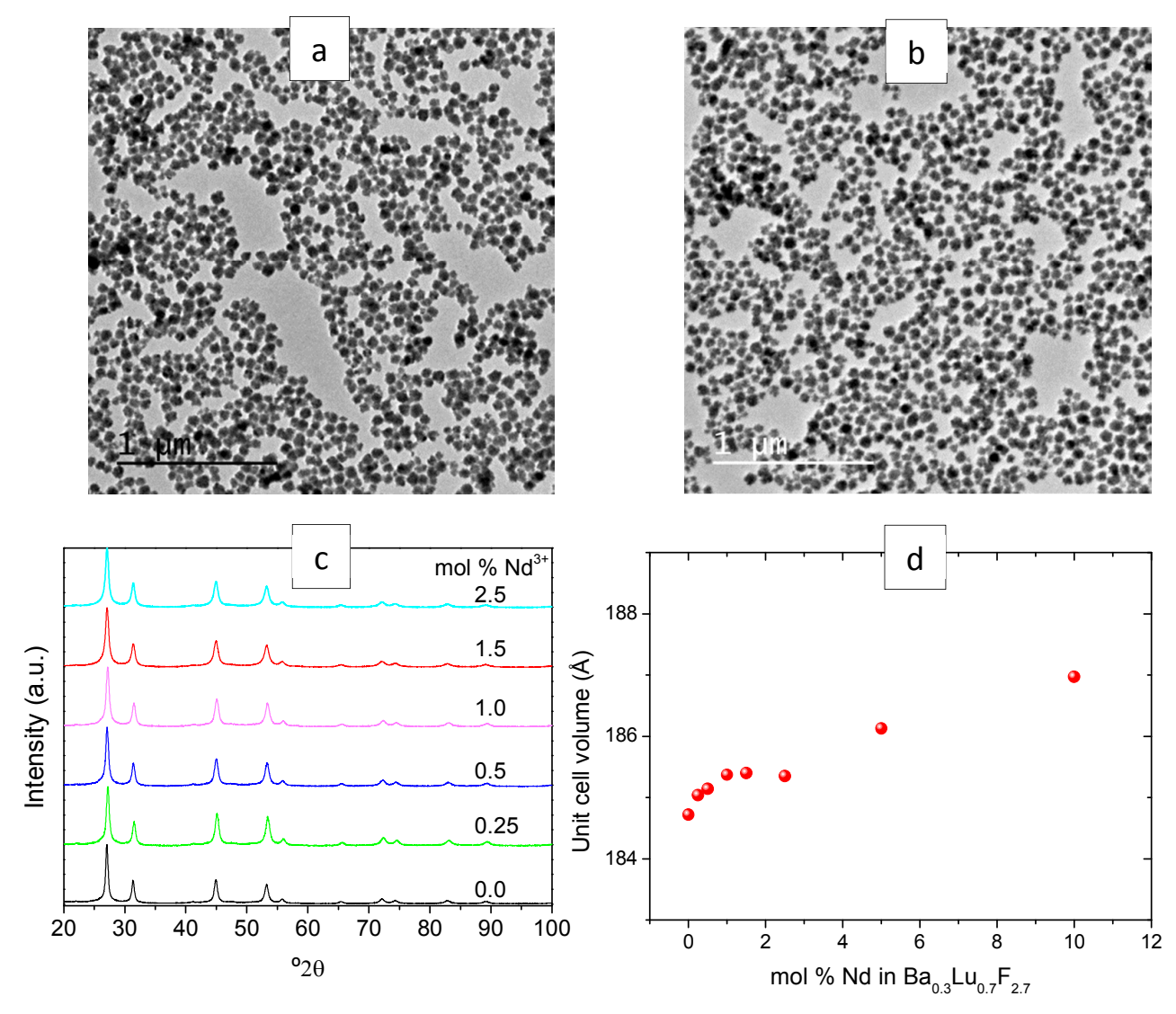
Figure 4
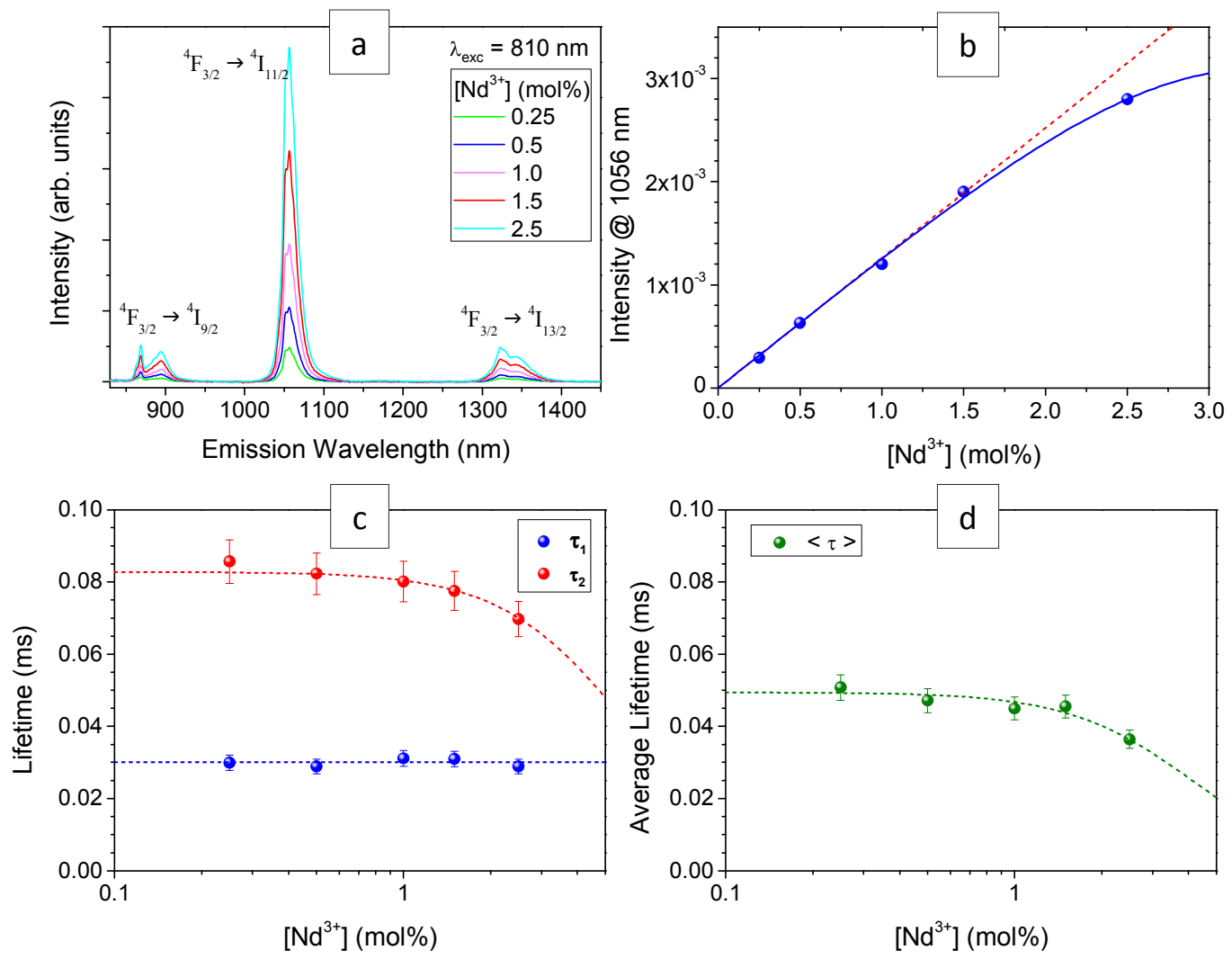
Figure 5
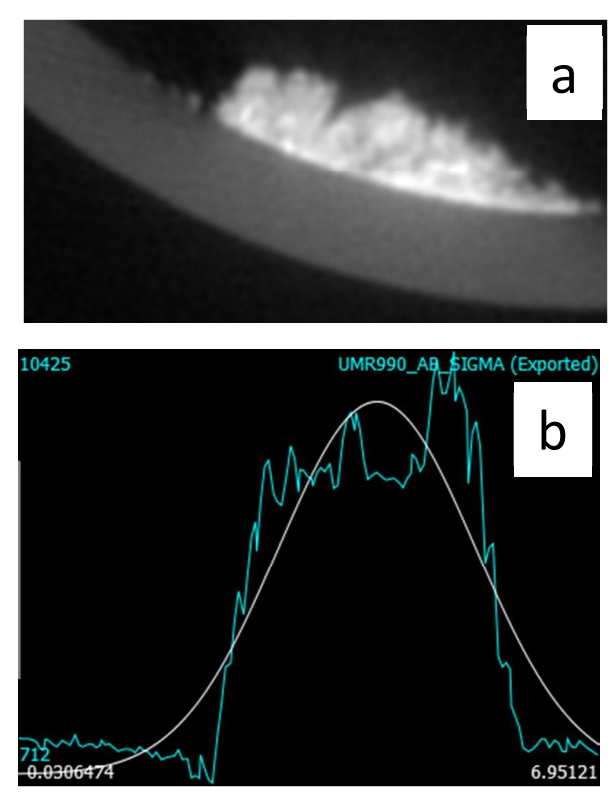
Table 1: Fitting Parameters of the Bi-exponential Temporal Dependence for the Luminescence Decay Curves of the $\mathrm{Nd}^{3+}$-Doped $\mathrm{Ba}_{0.3} \mathrm{Lu}_{0.7} \mathrm{~F}_{2.7}$ Nanophosphors Recorded at the Dominant Emission of the $\mathrm{Nd}^{3+}$ Ion.

\begin{tabular}{|c|c|c|c|c|c|}
\hline $\begin{array}{c}\text { [Nd] } \\
(\mathbf{m o l} \%)\end{array}$ & $\mathrm{I}_{\mathbf{0 1}}$ & $\begin{array}{c}\tau_{1} \\
(\mathbf{m s})\end{array}$ & $\mathbf{I}_{\mathbf{0 2}}$ & $\begin{array}{c}\tau_{\mathbf{2}} \\
(\mathbf{m s})\end{array}$ & $\begin{array}{c}<\tau> \\
(\mathbf{m s})^{\mathbf{a}}\end{array}$ \\
\hline 0.25 & 0.83 & 0.030 & 0.17 & 0.086 & 0.051 \\
\hline 0.5 & 0.85 & 0.029 & 0.15 & 0.082 & 0.047 \\
\hline 1 & 0.87 & 0.031 & 0.13 & 0.080 & 0.045 \\
\hline 1.5 & 0.85 & 0.031 & 0.15 & 0.078 & 0.046 \\
\hline 2.5 & 0.91 & 0.029 & 0.09 & 0.070 & 0.036 \\
\hline
\end{tabular}

${ }^{\mathrm{a}}$ The average lifetime $\langle\tau\rangle$ has been calculated from the right hand-side term of equation (2), using the corresponding fitting parameters. 


\section{Supporting Information}

\section{Crystal structure, NIR luminescence and X-ray computed tomography of $\mathrm{Nd}^{3+}: \mathrm{Ba}_{0.3} \mathbf{L u}_{0.7} \mathrm{~F}_{2.7}$ nanospheres}

Daniel González-Mancebo, ${ }^{a}$ Ana Isabel Becerro, ${ }^{a} *$ Eugenio Cantelar, ${ }^{b}$ Fernando Cussó, ${ }^{b}$ Arnaud Briat, ${ }^{c}$ Damien Boyer, ${ }^{d}$ Manuel Ocaña ${ }^{a}$

${ }^{a}$ Instituto de Ciencia de Materiales de Sevilla (CSIC-US), c/Américo Vespucio, 49, 41092 Seville, Spain

${ }^{b}$ Dpto. Física de Materiales, C-04. Universidad Autónoma de Madrid, 28049 Madrid (Spain).

${ }^{c}$ Université Clermont Auvergne, UMR 1240 INSERM, 58 rue Montalembert, BP184, 63005 Clermont-Ferrand Cedex

${ }^{d}$ Université Clermont Auvergne, CNRS, SIGMA Clermont, Institut de Chimie de Clermont-Ferrand, F-63000 Clermont-Ferrand, France

*Corresponding author: anieto@icmse.csic.es. Phone no: +34 954489545 


\section{Figure S1}
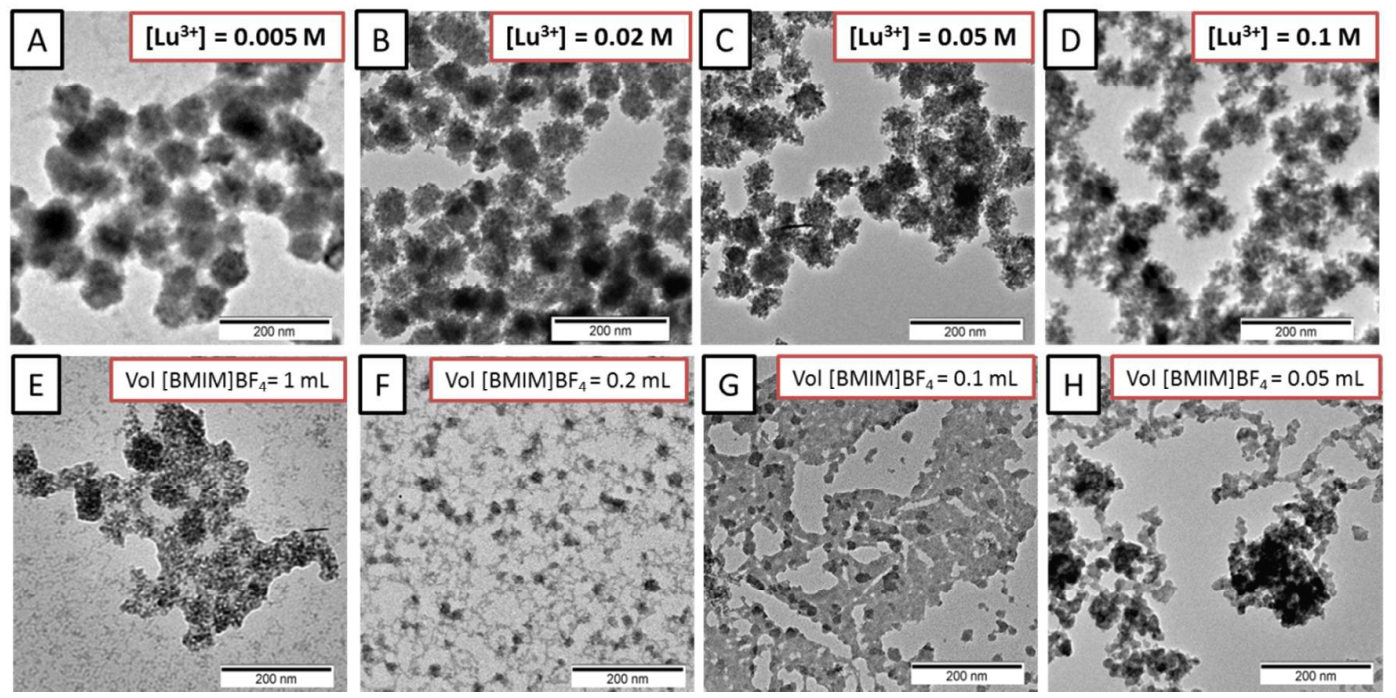

Figure S1: TEM micrographs of the precipitates obtained after changing only one of the parameters used to synthesise the uniform $\mathrm{Ba}_{0.3} \mathrm{Lu}_{0.7} \mathrm{~F}_{2.7}$ nanoparticles shown in Figure 1 of the paper. Top micrographs: Change of $\mathrm{Lu}$ acetate concentration. Bottom: Change of Fluoride concentration. 


\section{Figure S2}

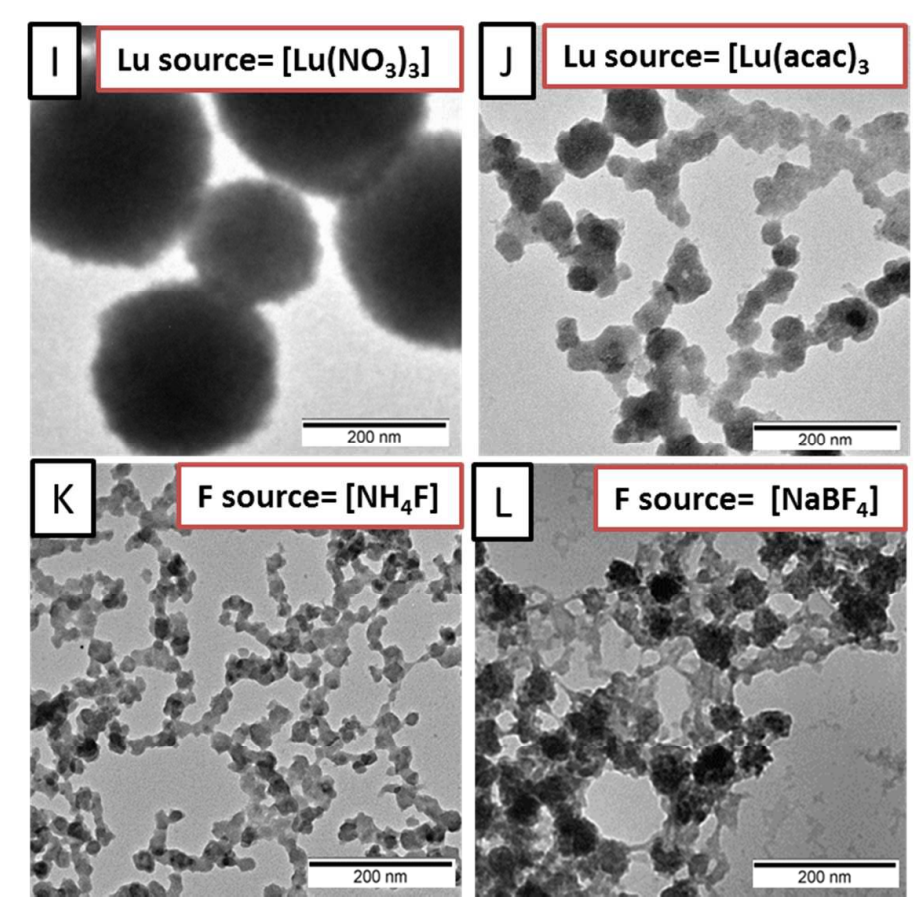

Figure S2: TEM micrographs of the precipitates obtained after changing only one of the parameters used to synthesise the uniform $\mathrm{Ba}_{0.3} \mathrm{Lu}_{0.7} \mathrm{~F}_{2.7}$ nanoparticles shown in Figure 1 of the paper. Top: Change of Lutetium precursor. Bottom: Change of fluoride precursor. 


\section{Figure S3}
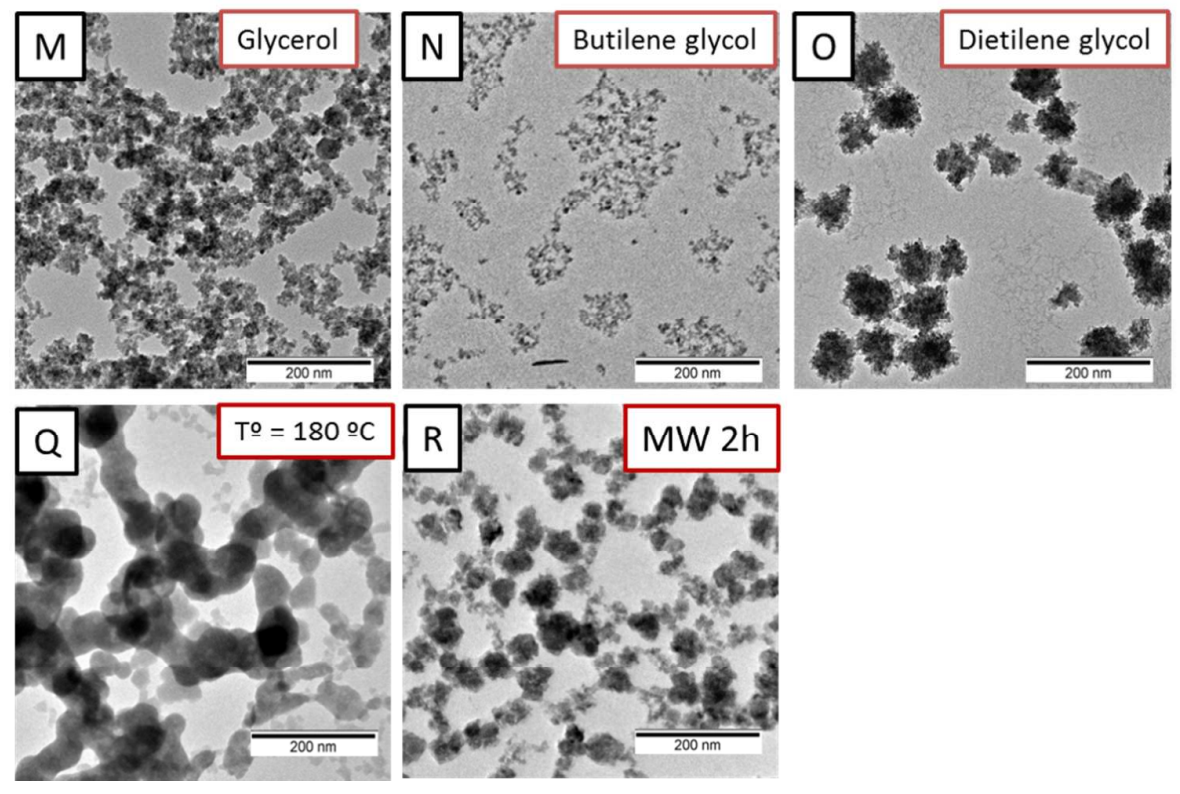

Figure S3: TEM micrographs of the precipitates obtained after changing only one of the parameters used to synthesise the uniform $\mathrm{Ba}_{0.3} \mathrm{Lu}_{0.7} \mathrm{~F}_{2.7}$ nanoparticles shown in Figure 1 of the paper. Top: Change of solvent nature. Bottom: Change of temperature (left) and of heating source (right). 
Figure S4
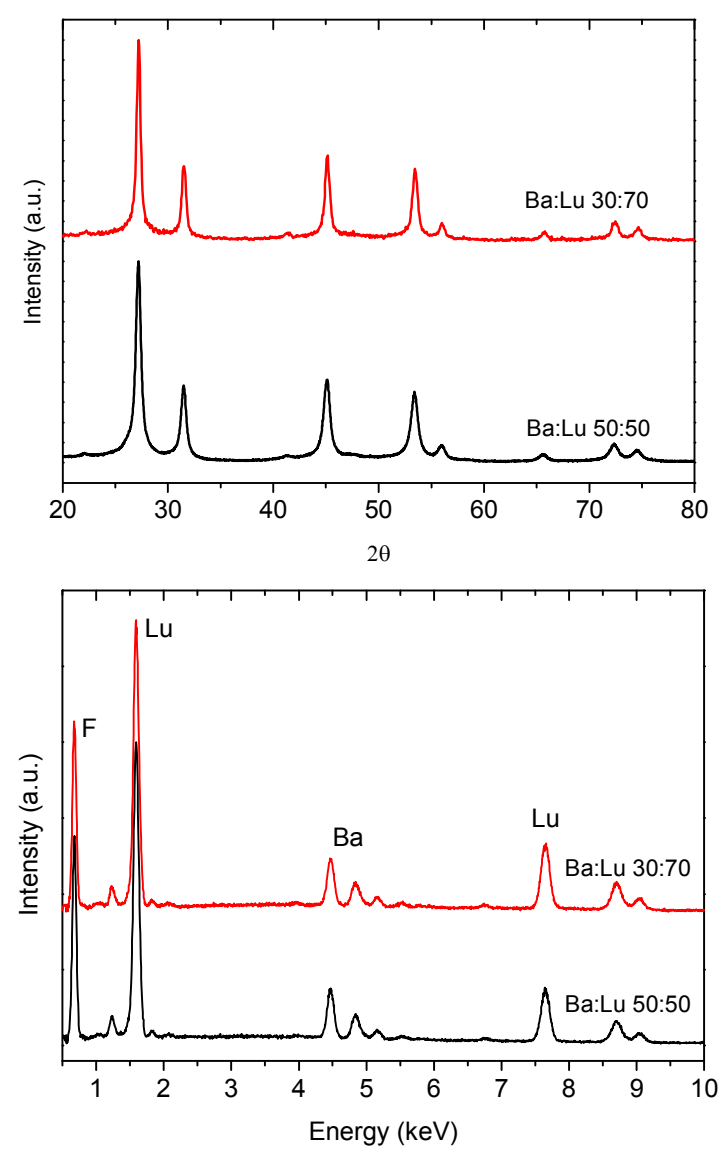

Figure S4: XRD patterns (top) and EDX spectra of the samples obtained from starting solutions containing a $\mathrm{Ba} / \mathrm{Lu} 50 / 50$ and $30 / 70$ stoichiometry. The EDX quantification results are also included. 
Figure S5

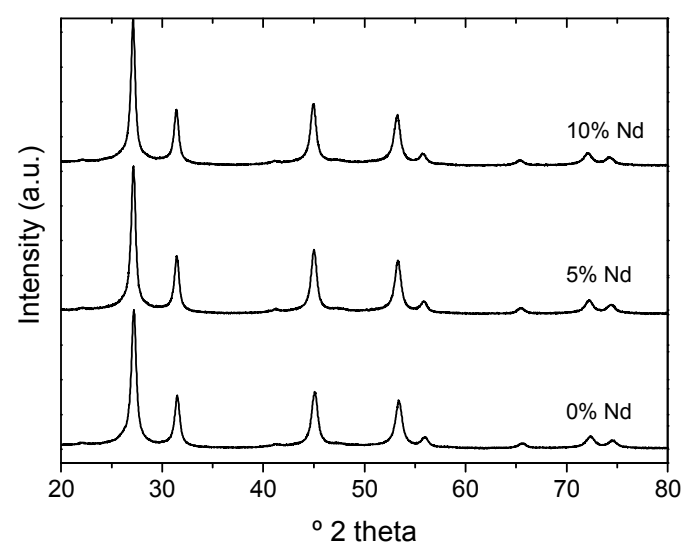

Figure S5: XRD patterns of the undoped and Nd-doped (5\% and $10 \%) \mathrm{Ba}_{0.3} \mathrm{Lu}_{0.7} \mathrm{~F}_{2.7}$ samples. 
Figure S6

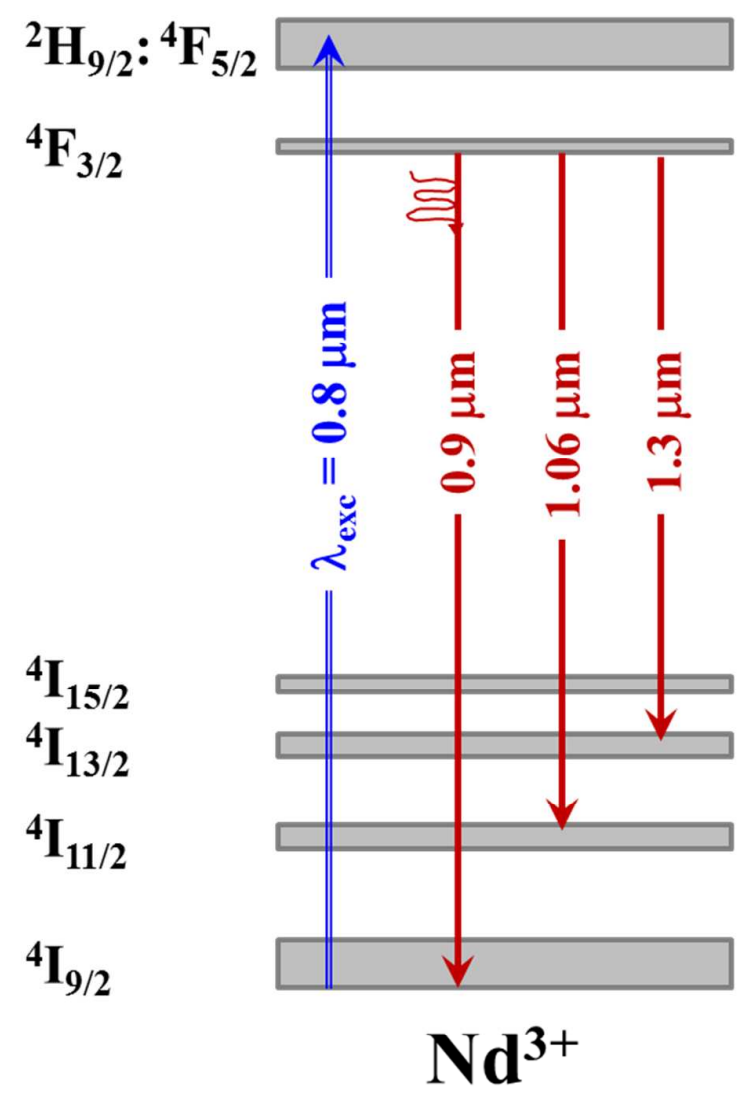

Figure S6: $\mathrm{Nd}^{3+}$ electronic energy levels diagram showing the non-radiative and radiative decays after excitation at $808 \mathrm{~nm}$. 


\section{Figure S7}
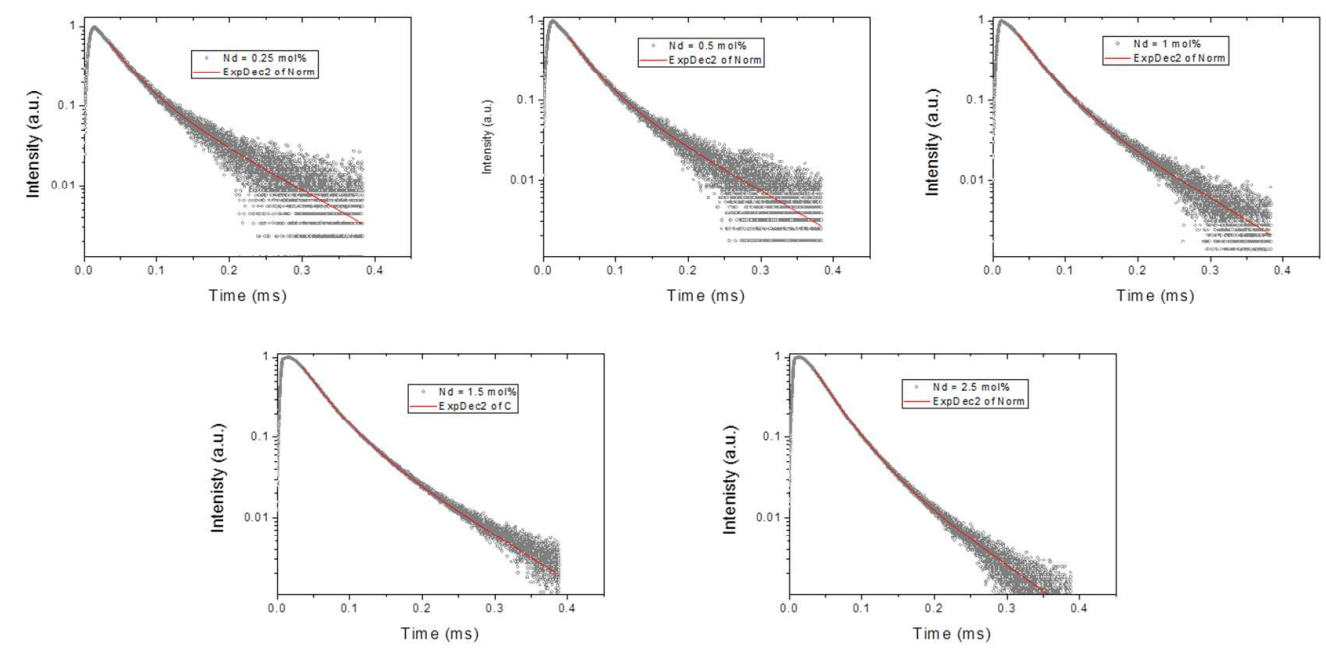

Figure S7: Temporal evolution of the ${ }^{4} \mathrm{~F}_{3 / 2}-{ }^{4} \mathrm{I}_{11 / 2}$ luminescence for the $\mathrm{Ba}_{0.3} \mathrm{Lu}_{0.7} \mathrm{~F}_{2.7}$ nanophosphors doped with $0.25,0.5,1.0,1.5$, and $2.5 \mathrm{~mol} \% \mathrm{Nd}^{3+}$ (excitation at $810 \mathrm{~nm}$ using a MOPO system). Solid lines correspond to the fitting of the experimental data assuming a bi-exponential luminescence decay, using eq 1 with the parameters given in Table 1 of the paper. 


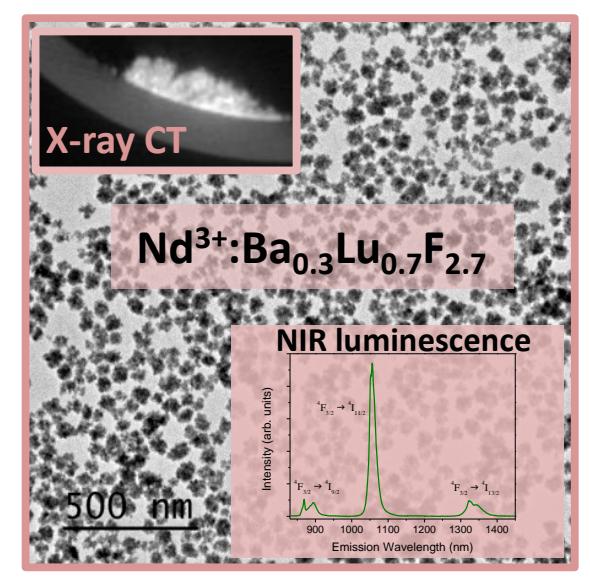

